\title{
On the Measurement of the Elasticity of Labour*
}

\author{
Charles Gottlieb $^{\dagger} \quad$ Joern Onken ${ }^{\ddagger} \quad$ Arnau Valladares-Esteban ${ }^{\S}$
}

\begin{abstract}
We use a simple theoretical framework, a building block of many macroeconomic models, to study the prominently debated relationship between the model parametrisation of the Frisch elasticity and the reduced-form evidence on the elasticity of labour. Focusing on tax holidays, we show that the elasticity measured with a reduced-form approach is only equal to the Frisch-elasticity parameter if there are no income or general equilibrium effects. Furthermore, for a wide range of standard values of the Frisch-elasticity parameter, the response of labour generated by a tax holiday in the model is aligned with the reduced-form evidence.
\end{abstract}

Keywords - Frisch Elasticity, Labour Supply, Aggregate Hours, Tax Holidays.

JEL Codes - E24, H21, J20.

*We would like to thank Timo Boppart, Michael Keane, and the anonymous referee for their comments. All errors are ours.

${ }^{\dagger}$ University of St. Gallen and Swiss Institute of Empirical Economic Research. Email: charles.gottlieb@unisg.ch.

¥University College London. Email: joern.onken.20@ucl.ac.uk.

$\S$ University of St. Gallen and Swiss Institute of Empirical Economic Research. Email: arnau.valladares@gmail.com. 


\section{Introduction}

The elasticity of labour is a critical element in the design and evaluation of public policies. From the optimal design of the tax system to the ability of the public sector to affect macroeconomic fluctuations, a wide range of relevant questions hinge on how much labour varies when wages change. There is a long-standing debate in Economics on the magnitude of this elasticity. The reduced-form studies suggest that the elasticity is relatively small, while macroeconomic models tend to use parametrisations that appear to contradict this evidence. Chetty, Guren, Manoli, and Weber (2012) clarify that, in many dimensions, macro models are in essence consistent with the reduced-form evidence. However, they single out the Frisch elasticity as the actual divergence.

The Frisch elasticity measures a percentage change in labour induced by a percentage change in wages while holding the marginal utility of wealth constant. Hence, it is only a well-defined concept when applied to constrained maximisation problems of individual utility functions. A common practice among macroeconomists is to use utility functions that capture the Frisch elasticity in a single parameter. Moreover, in many models, this parameter is a crucial ingredient (albeit not the only one) determining the response of aggregate labour to temporary changes in wages. ${ }^{1}$ When used to replicate the fluctuations of aggregate hours over the business cycle, the parametrisation of the Frisch-elasticity parameter suggests that relatively modest changes in wages imply significant variations in aggregate hours. Importantly, the source of wage variation over the business cycle in these models usually comes from the total factor productivity.

Several reduced-form studies have used arguably exogenous policy changes that affect net wages, mainly tax changes, to study the response of labour to changes in wages. ${ }^{2}$ Some of these analyses can only study a small population subgroup, making it difficult to link their estimates to the macroeconomic context. ${ }^{3}$ However, a set of papers have used tax holidays in Iceland and Switzerland to measure population-wide responses (Bianchi, Gudmundsson, and Zoega, 2001; Stefánsson, 2019; Sigurdsson, 2020; Martínez, Saez, and Siegenthaler, 2021). ${ }^{4}$ In line with the evidence on subgroups, the estimates from these tax holidays indicate that aggregate labour does not vary much when wages are temporarily untaxed. These findings have lead to the conjecture that the Frisch elasticity is small.

We use a simple framework, a building block of many macro models in the literature, to shed light on the relationship between the reduced-form evidence and the parametrisation of macro models. We make two contributions. First, we spell out the relationship between the Frischelasticity parameter and the change in aggregate labour produced by a tax change. We show that it is only possible to measure the Frisch elasticity directly from a tax holiday if the utility function exhibits no income effects and there are no general equilibrium effects in the economy.

\footnotetext{
${ }^{1}$ Keane and Rogerson $(2012,2015)$ provide clear reviews of the determinants of the elasticity of aggregate labour in rich structural models and its relationship with the reduced-form evidence.

${ }^{2}$ As Chetty et al. (2012) note, it is important to distinguish between analyses that measure changes between steady-states and those measuring changes near a steady-state. Our focus is on the latter. Keane (2011) provides a survey on the interaction between labour supply and taxes.

${ }^{3}$ See Gruber and Wise (1999), Card and Hyslop (2005), Brown (2013), and Manoli and Weber (2016). Carrington (1996) is able to estimate labour responses for the population of Alaska.

${ }^{4} \mathrm{~A}$ tax holiday occurs when the income earned during a particular period is untaxed due to a change in the tax system, generating temporary exogenous variation in net wages.
} 
Moreover, for the standard range of values used for the Frisch-elasticity parameter, the response of aggregate labour induced by a tax holiday in the model is in line with the reduced-form evidence. We provide estimates not only for Iceland and Switzerland but also for Canada, France, Germany, Italy, Japan, the United Kingdom, and the United States. In all cases, the standard range of parameters used in macro models is compatible with the magnitude of the estimates found in the reduced-form evidence. Second, we show that the response of aggregate labour to a tax holiday is generally different from that of a change in total factor productivity, the usual channel used to simulate business cycles. That is, the reduced-form estimates inferred from tax changes do not necessarily provide a direct measurement of the behaviour of aggregate labour over the business cycle in macro models.

The rest of the paper is organised as follows. In Section 2, we review the reduced-form evidence on labour responses to temporary changes in wages, focusing primarily on tax holidays. Section 3 present our theoretical framework. In Section 4, we apply our model to the case of tax holidays and obtain our main results. Section 5 concludes.

\section{The Reduced-form Evidence on the Elasticity of Labour}

A significant number of reduced-form papers try to measure how much labour changes when net wages change. ${ }^{5}$ The majority rely on arguably exogenous variation in taxes for identification. There is significant heterogeneity in sample composition, outcomes, and identification strategies used among these papers. Some can only analyse small subgroups of the population, some observe outcomes at the intensive margin, others only at the extensive margin, and some exploit permanent policy changes while others use temporary variations. Among all the available approaches in the reduced-form literature, those from tax holidays provide the best reference point to anchor the effect of the Frisch elasticity in macro models. These studies cover the whole population, typically provide estimates for the total variation in labour (intensive plus extensive margins), and use temporary changes in net wages.

To the best of our knowledge, the first paper to use a tax holiday to measure the response of labour is Bianchi et al. (2001). They study the tax holiday in Iceland in 1987 due to moving from an income tax based on previous year's income to a pay-as-you-earn system. During 1987, Iceland residents did pay income taxes. However, taxes were not based on 1987's income but on that of the previous year. For studying the Frisch elasticity, a critical drawback of the policy change in Iceland is that the average tax after the tax holiday was significantly lower than before ( $8.0 \%$ vs $14.5 \%$ ). Hence, there were temporary and permanent variations in wages occurring at the same time. Bianchi et al. (2001) combine different sources of administrative data to gather a sample of around 10,000 individuals for whom they observe filled income taxes and weeks worked before, during, and after the tax holiday. They measure an elasticity of weeks worked due to the tax holiday of 0.42 and an elasticity of earnings of 0.67 for the whole sample. Because Bianchi et al. (2001) do not observe hours worked and because wage rates changed in 1987, it is hard

\footnotetext{
${ }^{5}$ See Chetty et al. $(2011,2012)$ for a meta-analysis of the reduced-form literature.
} 
to classify these estimates as unequivocally measuring the intensive or the intensive margin, or both.

Sigurdsson (2020) uses a larger dataset of digitalised payslips and a more sophisticated reduced-form set of tools to analyse also the 1987 tax holiday in Iceland. He finds that the elasticity of weeks worked is 0.37 , while the estimate for the employment rate is 0.10 . Whereas the elasticity of the employment rate is an estimate of the extensive margin elasticity, it is again less clear which margin is measured through the elasticity of weeks worked. Nonetheless, the estimates in Sigurdsson (2020) are very similar in magnitude to those in Bianchi et al. (2001). Hence, it is very plausible that the elasticity of aggregate labour due to the tax holiday lies close to these estimates. ${ }^{6}$

Martínez et al. (2021) study a similar event to the tax holiday in Iceland that took place in the late 1990s among Swiss cantons. An important difference between the Icelandic and Swiss tax holidays is that the latter took place at different times in different cantons due to the country's federal structure. Martínez et al. (2021) estimate an elasticity of 0.025 for aggregate wage earnings due to the tax holiday. Their estimate is close to zero and an order of magnitude smaller than those from Iceland. As Sigurdsson (2020) discusses, there are important caveats to the analysis in Martínez et al. (2021). First, in their main analysis, the construction of the sample excludes people younger than 26-28 years old while also excluding people older than 62 . Younger and older people are likely to have relatively strong responses to changes in wages, as Sigurdsson (2020) finds. Second, as the authors note, the transition from the old to the new tax system included provisions to tax significant changes in income in the Swiss case. Third, Switzerland was a full-employment economy during the tax holiday period. Moreover, as Sigurdsson (2020) highlights, the Swiss economy tends to exhibit modest fluctuations in aggregate hours over the business cycle. That is, it is likely that frictions in the labour market dampened the effect of the tax holiday. ${ }^{7}$ In fact, Martínez et al. (2021) find that for the self-employed and high-earners, the elasticity is much closer to the estimates from Iceland (0.2 and 0.1).

Overall, with all the caveats mentioned above, our reading of the literature is that the reduced-form estimates for the elasticity of total aggregate labour (intensive plus extensive margins) due to tax holidays lie between being close to zero up to 0.5. It is worth noting that the meta-analysis in Chetty et al. (2012), which also includes papers that analyse population subgroups, suggests that the mean of the estimates in the reduced-form literature is about $0.86 .^{8}$ In Section 4, we dissect the mapping between these reduced-form estimates and the Frisch-elasticity parameter in our theoretical framework, which we lay out in the next section.

\footnotetext{
${ }^{6}$ Stefánsson (2019) also studies the Icelandic tax holiday using data on labour income and a differencein-difference approach. He obtains a wide range of estimates for the elasticity of labour income, from 0.07 to 4 . Hence, it is hard to establish a meaningful reference point from his analysis.

${ }^{7}$ Chetty (2012) provides a framework to derive bounds on the elasticity of labour due to frictions.

${ }^{8}$ The estimate in Chetty et al. (2012) does not include the results in Sigurdsson (2020) and Martínez et al. (2021) as these papers were not available at the time.
} 


\section{Framework}

The economy features a representative household, a representative firm, and a government. The representative household is forward-looking and faces labour-leisure and consumption-savings decisions. The representative firm combines labour and capital in a Cobb-Douglas production function which produces a numeraire good that is either consumed, invested, or used by the public sector. The government levies taxes on labour income and redistributes them in a lumpsum fashion. All markets are perfectly competitive.

Household. The representative household has preferences over consumption $\left(c_{t}\right)$ and hours worked $\left(h_{t}\right)$. The utility function is $U\left(c_{t}, h_{t}\right)$. The maximisation problem of the representative household is given by:

$$
\begin{gathered}
\mathbb{E} \sum_{t=0}^{\infty} \beta^{t} U\left(c_{t}, h_{t}\right), \\
\text { subject to } c_{t}+k_{t+1}=(1-\tau) w_{t} h_{t}+\left(1+r_{t}-\delta\right) k_{t}+T_{t},
\end{gathered}
$$

where $k_{t}$ is capital, $\tau$ is the marginal labour income tax rate, $w_{t}$ is the wage rate, $r_{t}$ is the rental price of capital, $\delta$ is the depreciation rate of capital, and $T_{t}$ are lump-sum transfers and.

The first-order optimality conditions of the representative household are: ${ }^{9}$

$$
\begin{aligned}
U_{c}\left(c_{t}, h_{t}\right) & =\beta\left(1+r_{t+1}-\delta\right) U_{c}\left(c_{t+1}, h_{t+1}\right), \text { and } \\
-\frac{U_{h}(c, h)}{U_{c}(c, h)} & =w_{t}(1-\tau) .
\end{aligned}
$$

The representative household chooses consumption equalising the current period marginal utility of consumption to the discounted marginal utility of consumption tomorrow. It chooses labour supply such that the rate of marginal utilities between consumption and labour equals the net wage.

Firm. The representative firm combines capital and labour to produce output. The production technology features constant returns to scale, and the capital share is denoted by $\alpha$. The first-order conditions of the representative firm are:

$$
\begin{array}{r}
w_{t}=(1-\alpha)\left(\frac{k_{t}}{h_{t}}\right)^{\alpha}, \text { and } \\
r_{t}=\alpha\left(\frac{k_{t}}{h_{t}}\right)^{\alpha-1} .
\end{array}
$$

The representative firm chooses capital and labour to maximise profits such that the marginal products of labour and capital equal their marginal cost.

\footnotetext{
${ }^{9}$ To shorten notation, we write the partial derivative $\frac{\partial U(x)}{\partial x}$ of a given function $U$ on a variable $x$ as $U_{x} . U_{x x}$ denotes $\frac{\partial U(x)}{\partial^{2} x}$.
} 
Government. The government taxes labour income at rate $\tau$ and redistributes tax revenues as a lump-sum transfer $T_{t}$ to households. The budget constraint of the government is:

$$
T_{t}=\tau w_{t} h_{t}
$$

Equilibrium. We are interested in studying the effects of temporary changes in taxes. For this purpose, we linearise the equilibrium conditions around the steady state of the economy. It is important to highlight that a temporary deviation from the steady-state is the closest theoretical counterpart to the tax holidays exploited in the reduced-form literature. The linearised equilibrium is summarised in the following equations: ${ }^{10}$

$$
\begin{array}{r}
-\epsilon_{c} \hat{c}_{t}+\frac{U_{c h}}{U_{c}} h \hat{h}_{t}+\epsilon_{c} \hat{c}_{t+1}-\frac{U_{c h}}{U_{c}} h \hat{h}_{t+1}-\frac{r}{1+r} \hat{r}_{t}=0, \\
\Psi_{u} \hat{h}_{t}+\Psi_{c} \hat{c}_{t}-\hat{w}_{t}+\frac{\tau}{1-\tau} \hat{\tau}_{t}=0, \\
c \hat{c}_{t}+k \hat{k}_{t+1}=w(1-\tau) h\left(\hat{w}_{t}+\hat{h}_{t}-\frac{\tau}{1-\tau} \hat{\tau}_{t}\right)+\frac{k}{\beta} \hat{k}_{t}+r k \hat{r}_{t}+T \hat{T}_{t}, \\
\hat{w}_{t}=\alpha\left(\hat{k}_{t}-\hat{h}_{t}\right), \\
\hat{r}_{t}=(\alpha-1)\left(\hat{k}_{t}-\hat{h}_{t}\right), \text { and } \\
\hat{T}_{t}=\hat{\tau}_{t}+\hat{w}_{t}+\hat{h}_{t} .
\end{array}
$$

Equations 6 and 7 are the linearised first-order conditions of the household maximisation problem. They determine household behaviour. Equation 8 is the linearised budget constraint of the household. Equations 9 and 10 are the factor prices from the firm's maximisation problem. Equation 11 is the linearised government's budget constraint. ${ }^{11}$

The Frisch elasticity is $\epsilon_{u}=\frac{U_{h}}{h\left(U_{h h}-\frac{U_{c h}^{2}}{U_{c c}}\right)}$. That is, the percentage change in labour due to a percentage change in wages while keeping the marginal utility of the budget constraint multiplier (wealth) constant. Further, we define $\epsilon_{c}=-\frac{U_{c c} c}{U_{c}}$ as the Arrow-Pratt measure of relative risk aversion. Finally, we define $\Psi_{u}=\left(\frac{1}{\epsilon_{u}}+\frac{h}{U_{h}}\left(\frac{U_{h c}^{2}}{U_{c c}}-\frac{U_{h}}{U_{c}} U_{c h}\right)\right)$ and $\Psi_{c}=\left(c \frac{U_{h c}}{U_{h}}+\epsilon_{c}\right)$ to ease exposition.

\section{The Tax Elasticity of Aggregate Labour}

In this framework, the tax elasticity of aggregate labour amounts to the relative change in aggregate labour $\left(\hat{h}_{t}\right)$ with respect to a change in taxes $\left(\hat{\tau}_{t}\right){ }^{12}$

We derive two versions of the tax elasticity of aggregate labour. First, we assume that wages, the rate of return of capital, and the level of capital do not change with respect to the steady state $\left(\hat{r}_{t}=\hat{w}_{t}=\hat{k}_{t}=\hat{k}_{t+1}=0\right) .{ }^{13}$ We label this derivation the partial equilibrium $(P E)$ tax

\footnotetext{
${ }^{10}$ We denote the steady-state equilibrium level of an aggregate variable as $x . x_{t}$ is the level of the variable at time $t$, and $\hat{x}_{t}$ is the percentage change with respect to the steady state. That is, $\hat{x}_{t}=\frac{x_{t}-x}{x}$.

${ }^{11}$ We provide the definition of the equilibrium in Appendix Section A.

${ }^{12}$ We detail the steps of all derivations in this section in Appendix Section B.1.

${ }^{13}$ Throughout the analysis, we assume that capital is unchanged from its steady-state level. Letting
} 
elasticity of aggregate labour:

$$
\epsilon^{P E}=\frac{\hat{h}_{t}}{\hat{\tau}_{t}}=-\frac{\tau}{1-\tau} \frac{1}{\Psi_{u}+\Psi_{c}(1-\alpha) \frac{y}{c}} .
$$

Equation 12 shows that for any utility function $U\left(c_{t}, h_{t}\right)$, the tax elasticity of aggregate labour depends on the level of taxes $(\tau)$, preferences $\left(\Psi_{u}\right.$ and $\left.\Psi_{c}\right)$, the labour income share of the production function $(1-\alpha)$, and the consumption-to-income ratio $\left(\frac{y}{c}\right)$, even in partial equilibrium. When we allow for changes in factor prices, i.e. when there are general equilibrium effects, the tax elasticity of aggregate labour is given by:

$$
\epsilon=\frac{\hat{h}_{t}}{\hat{\tau}_{t}}=-\frac{\tau}{1-\tau} \frac{1}{\Psi_{u}+\Psi_{c}(1-\alpha) \frac{y}{c}+\alpha}
$$

where $\alpha$ is the capital income share which now affects the response of labour due to the change in the price of capital.

Equations 12 and 13 indicate that additional assumptions are needed to empirically measure the Frisch elasticity (a component of $\Psi_{u}$ ) out of an empirical estimate of the tax elasticity of labour supply $(\epsilon)$, which is what is measured in reduced-form analyses. To clearly illustrate the relationship between the Frisch elasticity and the tax elasticity of aggregate labour, we focus on two widely used utility functions. We look at ? preferences (MaC hereafter) and Greenwood, Hercowitz, and Huffman (1988) preferences (GHH hereafter). ${ }^{14}$ These two are broadly used within the class of preferences consistent with a balanced-growth path with nonconstant aggregate hours. In the GHH case, there are no income effects, only substitution effects. On the other hand, with $\mathrm{MaC}$ preferences, the income effect is one of the determinants of labour supply. ${ }^{15}$

GHH Preferences. The period utility over consumption $\left(c_{t}\right)$ and labour $\left(h_{t}\right)$ is given by:

$$
U\left(c_{t}, h_{t}\right)=\frac{1}{1-\gamma}\left(c_{t}-\frac{h_{t}^{1+\frac{1}{\phi}}}{1+\frac{1}{\phi}}\right)^{1-\gamma}
$$

where $\phi>0$ defines the Frisch elasticity, and $\gamma$ the risk aversion. For these preferences, the partial equilibrium tax elasticity of aggregate labour is:

$$
\epsilon_{\mathrm{GHH}}^{P E}=-\frac{\tau}{1-\tau} \phi
$$

In this case, it is possible to estimate the Frisch elasticity $(\phi)$ from an estimate of the tax elasticity of aggregate labour $\left(\epsilon_{\mathrm{GHH}}^{P E}\right)$ without having to take into consideration any other structural

capital vary diffuses the effect of a tax change over several periods rendering the exercise less transparent. Moreover, as we focus on temporary tax changes to bring the model to the data, this assumption is in line with the framework used by the reduced-form analyses, which do not find dynamic responses of aggregate labour.

${ }^{14}$ Our analysis also nests the King, Plosser, and Rebelo (1988) preferences, a particular case within the ? class, where the risk aversion parameter is 1 .

${ }^{15}$ See Boppart and Krusell (2020) for an analysis of the interaction between income effects, the balanced growth path, and the historical evidence on aggregate hours worked. 
element of the economy. With general equilibrium effects, the tax elasticity of aggregate labour is:

$$
\epsilon_{\mathrm{GHH}}=-\frac{\tau}{1-\tau} \frac{1}{\frac{1}{\phi}+\alpha}
$$

The existence of general equilibrium effects implies that one requires empirical estimates of both the tax elasticity of aggregate labour $\left(\epsilon_{\mathrm{GHH}}\right)$ and the capital income share $(\alpha)$, along with the level of taxes $(\tau)$, to compute the Frisch elasticity $(\phi)$. The takeaway is that general equilibrium effects play a role in determining the tax elasticity of aggregate labour. The economy's structure will shape the precise form how these general equilibrium effects mediate the relationship between the Frisch elasticity and the tax elasticity of aggregate labour concretely.

MaC Preferences. The period utility over consumption $\left(c_{t}\right)$ and labour $\left(h_{t}\right)$ is given by:

$$
U\left(c_{t}, h_{t}\right)=\frac{c_{t}^{1-\gamma}}{1-\gamma}-\frac{h_{t}^{1+\frac{1}{\phi}}}{1+\frac{1}{\phi}},
$$

where $\phi>0$ also captures the Frisch elasticity, and $\gamma$ the risk aversion. With these preferences, both the partial and general equilibrium cases deliver expressions of the tax elasticity of aggregate labour that include more elements than the Frisch elasticity alone. In partial equilibrium, the tax elasticity of aggregate labour is:

$$
\epsilon_{\mathrm{MaC}}^{P E}=-\frac{\tau}{1-\tau} \frac{1}{\frac{1}{\phi}+\gamma(1-\alpha) \frac{y}{c}} .
$$

Including general equilibrium effects, we obtain:

$$
\epsilon_{\mathrm{MaC}}=-\frac{\tau}{1-\tau} \frac{1}{\frac{1}{\phi}+\gamma(1-\alpha) \frac{y}{c}+\alpha} .
$$

In this case, we see the role of income effects in shaping the model response to a tax change. Similarly to the discussion on general equilibrium effects, the general point is that it is likely that there are other preferences' fundamentals, apart from the Frisch elasticity, determining the response of aggregate labour. In sum, reduced-form studies measure an elasticity $(\epsilon)$ that depends on the Frisch elasticity but also on additional model parameters, even in our simple case. In the next section, we parametrise the expressions we obtain for the tax elasticities of aggregate labour to study the relationship between the Frisch elasticity and the reduced-form estimates from tax holidays.

\section{Tax Holidays and the Frisch Elasticity}

As we discuss in Section 2, tax holidays provide the best reduced-form estimates to link the Frisch elasticity in macro models to the data. Both tax holidays in Iceland and Switzerland temporarily reduced taxes on income. However, other taxes that might affect the allocation of the economy remained in place. In order to provide a better mapping between our framework and the data, we enrich the tax system by distinguishing among taxes on consumption $\left(\tau^{c}\right)$, investment $\left(\tau^{x}\right)$, 
labour income $\left(\tau^{i n c}\right)$, social security $\left(\tau^{s s}\right)$, and capital income $\left(\tau^{k}\right)$. The budget constraint in the household maximisation problem becomes:

$$
\left(1+\tau^{c}\right) c_{t}+\left(1+\tau^{x}\right) x_{t}=\left(1-\tau^{i n c}-\tau^{s s}\right) w_{t} h_{t}+\left(1-\tau^{k}\right)\left(r_{t}-\delta\right) k_{t}+\delta k_{t}+T_{t}
$$

In our framework, a tax holiday corresponds to a deviation from the steady state in which the labour income tax is zero $\left(\hat{\tau}^{i n c}=-1\right)$. Following an analogous process to that in Section 3 , we derive the tax elasticities of aggregate labour measured in a tax holiday: ${ }^{16}$

$$
\begin{aligned}
\xi_{\mathrm{GHH}}^{P E} & =\frac{\tau^{i n c}}{1-\tau^{i n c}-\tau^{s s}} \phi \\
\xi_{\mathrm{GHH}} & =\frac{\tau^{i n c}}{1-\tau^{i n c}-\tau^{s s}} \frac{1}{\frac{1}{\phi}+\alpha}, \\
\xi_{\mathrm{MaC}}^{P E} & =\frac{\tau^{i n c}}{1-\tau^{i n c}-\tau^{s s}} \frac{1}{\frac{1}{\phi}+\gamma(1-\alpha) \frac{y}{c}}, \text { and } \\
\xi_{\mathrm{MaC}} & =\frac{\tau^{i n c}}{1-\tau^{i n c}-\tau^{s s}} \frac{1}{\frac{1}{\phi}+\gamma(1-\alpha) \frac{y}{c}+\alpha} .
\end{aligned}
$$

Note that the taxes that play a role in the determination of the tax elasticity of aggregate labour are the labour income tax $\left(\tau^{i n c}\right)$ and the social security tax $\left(\tau^{s s}\right)$. The sign of the tax elasticities is the opposite of that in Section 3 because the definition of a tax holiday is a decrease in marginal labour income taxes.

\subsection{Parametrisation}

We follow Prescott (2004) to parametrise our framework to Iceland and Switzerland, the two countries for which we have reduced-form estimates from tax holidays. We use national accounts data from the United Nations System of National Accounts (SNA) and the Organisation for Economic Co-operation and Development (OECD). For Switzerland, the data available allows us to measure the consumption-to-income ratio $\left(\frac{c}{y}\right)$, the capital share $(\alpha)$ and the tax rates $\left(\tau^{i n c}\right.$ and $\left.\tau^{s s}\right)$ by taking averages of the relevant national accounts in the 1995-2005 period, around the tax holiday years. ${ }^{17}$ However, the necessary data to parametrise the framework is not available for Iceland before the year 2000. We use data for 2000-2010 to compute the averages for Iceland as these are the years with the relevant data available closest to the tax holiday. Table 1 presents all the parameter values we use.

\subsection{Results}

With the inputs from Section 4.1, we can illustrate the relationship between the measured elasticity ( $\xi$ in Equations $14,15,16$, and 17$)$ and the Frisch elasticity $(\phi)$. Figure 1 plots the

\footnotetext{
${ }^{16}$ All the steps to derive these expressions are in Appendix Section B.2.

${ }^{17}$ We follow the methodology proposed by Prescott (2004) to obtain marginal tax rates out of the average rates that can be computed from national accounts. The marginal tax rates calculated are close to those obtained using the methodology in Feenberg and Coutts (1993) for the U.S. both for the 1970-74 and $1993-96$ periods.
} 
Table 1: Data inputs to parametrise the framework to Iceland and Switzerland.

\begin{tabular}{lcccc} 
& $\frac{c}{y}$ & $\alpha$ & $\tau^{s s}$ & $\tau^{i n c}$ \\
\hline \hline Iceland & 0.77 & 0.35 & 0.07 & 0.32 \\
& 0.009 & 0.016 & 0.002 & 0.006 \\
Switzerland & 0.68 & 0.34 & 0.11 & 0.22 \\
& 0.005 & 0.003 & 0.001 & 0.002 \\
\hline
\end{tabular}

Notes: We compute all inputs following the methodology detailed in Prescott (2004). The inputs for Iceland are yearly averages from 2000-2010. For $\frac{c}{y}, 2004$ and 2005 are omitted in the average for Iceland as there is no data on aggregate consumption. The inputs for Switzerland are yearly averages from 19952005. We compute the value for each input for all available years and then compute the mean for the relevant period. We report the standard errors of the estimates in brackets.

relationship between the measured and Frisch elasticities using GHH preferences for Iceland and Switzerland, both in partial and general equilibrium. The solid black line in Panels 1a and 1c depicts Equation 15, while Panels 1b and 1d correspond to Equation 14.

We set the vertical axis of all plots to display only the plausible range of measured elasticities according to the reduced-form evidence on tax holidays, that is, between zero and 0.5 (see Section 2). Hence, the inverse images of the functions plotted indicate the range of Frisch elasticities consistent with the reduced-form evidence in our framework. For example, in Panel 1a we see that a Frisch elasticity between zero and 1.5 is consistent with the reduced-form evidence using GHH preferences in general equilibrium (zero to 0.5 on the vertical axis). In other words, $[0,1.5]$ is the range of values that can be used to parametrise the Frisch elasticity such that the model is aligned with the magnitude of the reduced-form evidence (using GHH preferences and calibrating the model to Iceland).

Among the range of standard preferences used in macro models, the GHH are the limiting case of no income effects. Hence, they provide few degrees of freedom for the theoretical framework to replicate the data. Nonetheless, our results indicate that even in this simple environment, there is significant overlap between the implied measured elasticities by the values typically used to calibrate the Frisch elasticity, $\phi \in[1,4]$, and the reduced-form evidence. For example, for Switzerland in general equilibrium (Figure 1c), a Frisch elasticity between 1 and 3 implies a measured elasticity between 0.25 and 0.49 .

In the more common case of $\mathrm{MaC}$ preferences, the framework offers an additional degree of freedom, the risk aversion parameter $(\gamma)$, to link the Frisch and measured elasticities. To illustrate the role of this parameter transparently, we proceed as follows. In all plots of Figure 2, the solid black line is the standard case of log utility in consumption $(\gamma=1)$. The grey area represents all cases between $\gamma=0.5$ and $\gamma=2.5$, covering the standard range of values used for the risk aversion parameter in macro calibrations. Our results show that, with MaC preferences, almost all the range of standardly used values for the Frisch elasticity parameter $(\phi \in[1,4])$ are consistent with the reduced-form evidence. Because MaC preferences are the polar case of GHH preferences regarding the income effect, our results indicate that the magnitude of the income effect is a key determinant of the consistency between the model Frisch elasticity and the measured elasticity in our framework. 
Figure 1: The relationship between the Frisch and measured elasticities with GHH preferences.

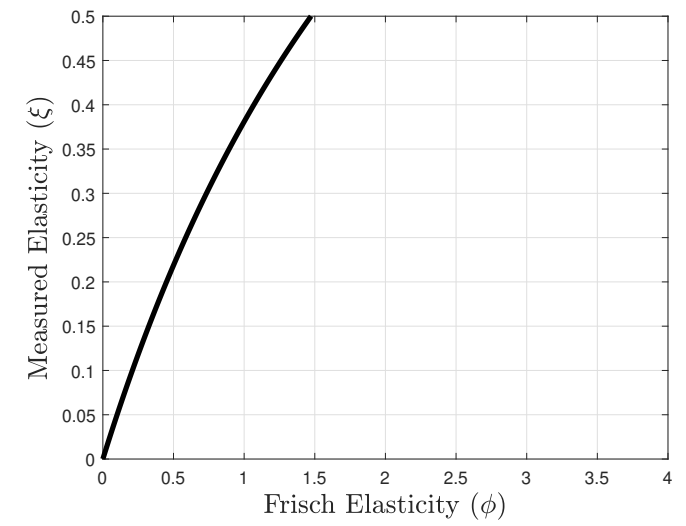

(a) Iceland with general equilibrium effects.

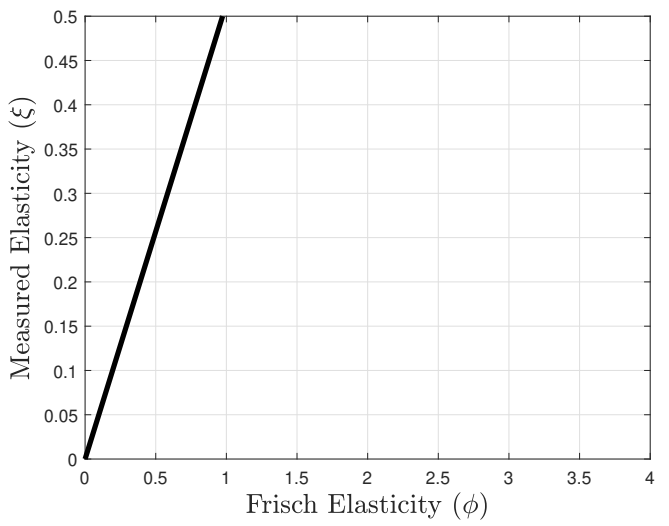

(b) Iceland in partial equilibrium.
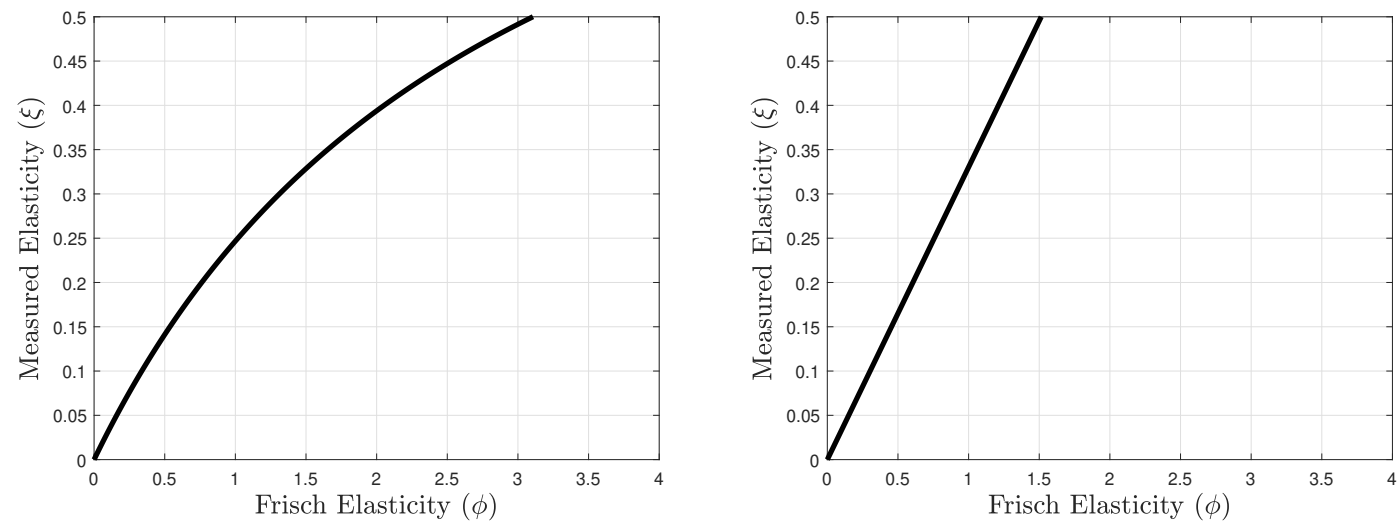

(c) Switzerland with general equilibrium effects.

(d) Switzerland in partial equilibrium.

Notes: Panels 1a and 1c plot Equation 15. Panels 1b and 1d plot Equation 14. The input values are in Table 1.

To further the scope of our results, we look at the G-7 countries (Canada, France, Germany, Italy, Japan, the United Kingdom, and the United States). We compute the range of measured elasticities associated with the Frisch elasticities typically used to calibrate macro models, between 1 and 3, for each country and each of the four cases we study. We present the computed ranges in Table 2. For example, in the case of the U.S., we see that a Frisch elasticity of 1 is associated with a measured elasticity of at least 0.08 , while a Frisch elasticity of 3 implies a measured elasticity of at most 0.27 , with $\mathrm{MaC}$ preferences in general equilibrium.

The estimates in Table 2 confirm the two main patterns in our results. First, the role of general equilibrium effects in dampening the response of aggregate labour to changes in taxes. The impact of the general equilibrium effects on the measured elasticity stems from the shape of the labour demand. In partial equilibrium, a reduction in taxes simply increases net wages and generates an increase in labour supply. When general equilibrium effects are factored in, the increase in labour supply is met with a decrease in the equilibrium wage, which dampens the response of aggregate labour. Secondly, the income effect also mutes the response of aggregate labour. Both in general and partial equilibrium, measured elasticities are lower with GHH preferences than with $\mathrm{MaC}$ preferences for all economies. A reduction in taxes implies a higher 
Figure 2: The relationship between the Frisch and measured elasticities with $\mathbf{M a C}$ preferences.

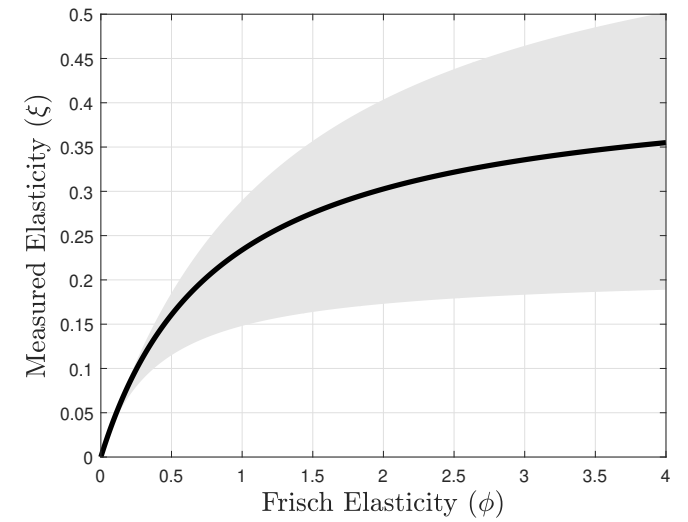

(a) Iceland with general equilibrium effects.

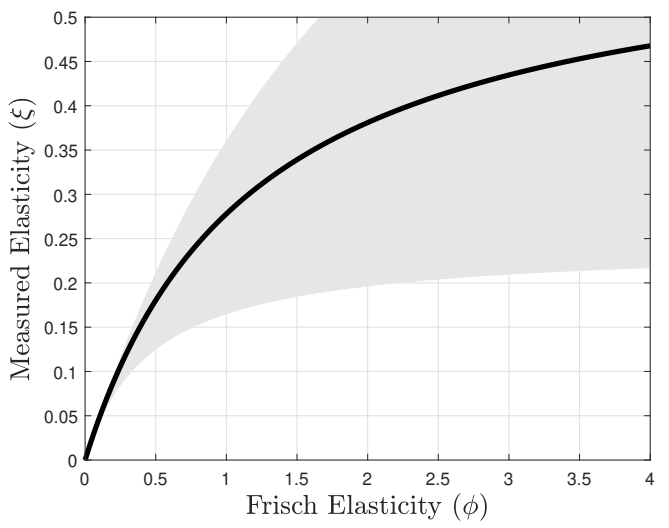

(b) Iceland in partial equilibrium.
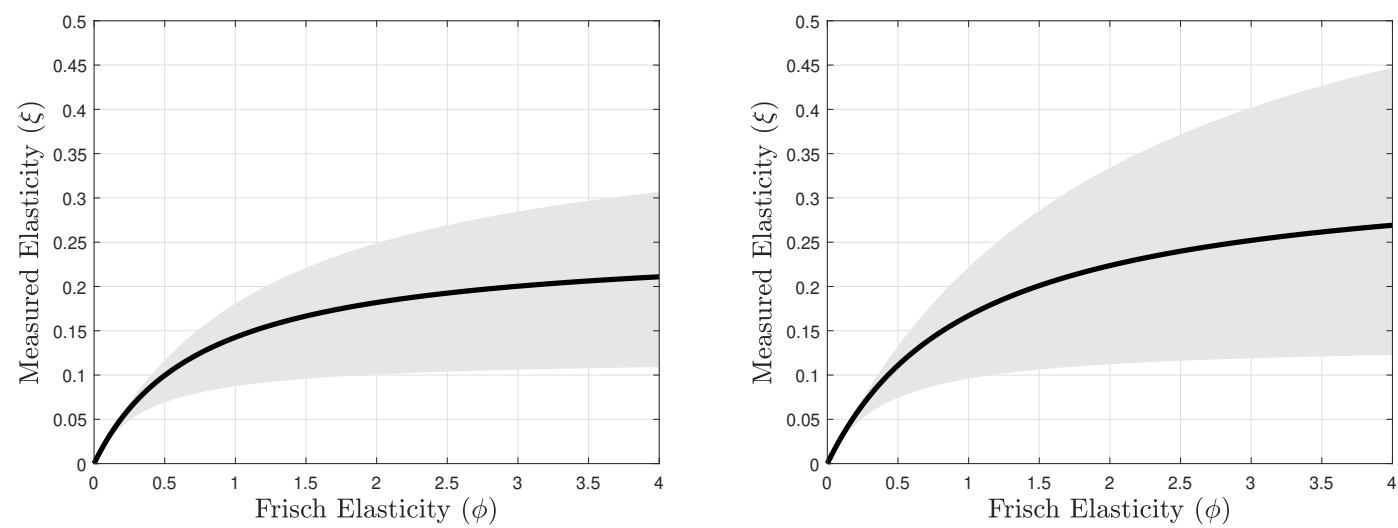

(c) Switzerland with general equilibrium effects. (d) Switzerland in partial equilibrium.

Notes: Panels 2a and 2c plot Equation 17 using the input values in Table 1 for Iceland and Switzerland, respectively. Panels $2 \mathrm{~b}$ and $2 \mathrm{~d}$ plot Equation 16 using the input values in Table 1 for Iceland and Switzerland, respectively. We plot the grey area by computing the minimum and maximum of all measured elasticities in $\gamma \in[0.5,2.5]$. The solid black line corresponds to $\log$ utility in consumption $(\gamma=1)$.

net wage rate. With only substitution effects (GHH preferences), the amount of labour supplied by the household increases because the shadow price of leisure increases with respect to that of consumption. The income effect in $\mathrm{MaC}$ preferences counterbalances the substitution effect. A higher net wage implies that any given amount of consumption is affordable while enjoying more leisure. In other words, with GHH preferences, the ratio between the marginal utility of consumption and leisure only depends on labour. In contrast, in the $\mathrm{MaC}$ case, it depends both on the level of labour and consumption.

\subsection{Implications}

Overall, our results suggest that there is plenty of room for standard macro models to be aligned with the reduced-form evidence on the response of aggregate labour to temporary changes in wages. We intentionally use a simple framework to expose clearly the relevant channels that connect the model Frisch elasticity to the measured tax elasticity of aggregate labour. In more complex models, the tax elasticity of aggregate labour depends on more components than in 
Table 2: Frisch elasticities in the standard range $\phi \in[1,3]$ are consistent with the reduced-form evidence from tax holidays.

\begin{tabular}{lcccc} 
& \multicolumn{2}{c}{ GHH preferences } & \multicolumn{2}{c}{ MaC preferences } \\
& PE & GE & PE & GE \\
\hline \hline Canada & {$[0.39,1.16]$} & {$[0.28,0.55]$} & {$[0.12,0.51]$} & {$[0.11,0.34]$} \\
France & {$[0.43,1.30]$} & {$[0.33,0.66]$} & {$[0.13,0.54]$} & {$[0.12,0.39]$} \\
Germany & {$[0.40,1.20]$} & {$[0.29,0.57]$} & {$[0.12,0.52]$} & {$[0.11,0.35]$} \\
Iceland & {$[0.51,1.54]$} & {$[0.38,0.74]$} & {$[0.17,0.68]$} & {$[0.15,0.46]$} \\
Italy & {$[0.52,1.57]$} & {$[0.37,0.69]$} & {$[0.18,0.72]$} & {$[0.15,0.46]$} \\
Japan & {$[0.17,0.51]$} & {$[0.12,0.23]$} & {$[0.06,0.23]$} & {$[0.05,0.15]$} \\
Switzerland & {$[0.33,0.99]$} & {$[0.25,0.49]$} & {$[0.09,0.39]$} & {$[0.09,0.28]$} \\
United Kingdom & {$[0.39,1.17]$} & {$[0.29,0.57]$} & {$[0.13,0.54]$} & {$[0.12,0.36]$} \\
United States & {$[0.29,0.87]$} & {$[0.22,0.44]$} & {$[0.09,0.38]$} & {$[0.08,0.27]$} \\
\hline
\end{tabular}

Notes: We compute the lower bound of the estimates in the column of GHH preferences in partial equilibrium using Equation 14 with $\phi=1$. The upper bound corresponds to $\phi=3$. We apply the same procedure to compute the estimates in the column of GHH preferences in general equilibrium, but we use Equation 15. For the $\mathrm{MaC}$ preferences in partial equilibrium, we use Equation 16 to compute a set of measured elasticities implied by the parameter space $\phi \in[1,3] \times \gamma \in[0.5,2.5]$. The lower bound of the range is the minimum of the computed measured elasticities, while the upper bound is the maximum. We apply the same procedure to compute the estimates in the column of MaC preferences in general equilibrium, but we use Equation 17. We report all parametrisation inputs for all countries in Table 4 in Appendix Section C.

our framework. Both Chetty et al. (2012) and Erosa, Fuster, and Kambourov (2016) provide simulations of the tax holiday in Iceland using richer frameworks than ours.

Erosa et al. (2016) use a heterogenous-agents lifecycle model with risky non-linear earnings, borrowing constraints, and labour market frictions, which is calibrated to men. Their model features heterogeneity in preferences using a MaC utility function with log utility in consumption and a Frisch-elasticity parameter equal to 2 . They generate an experiment in their model that mimics the tax holiday in Iceland and find an elasticity of aggregate labour of 0.64 , which is of the same order of magnitude as those found by the reduced-form papers. There are many more factors shaping the response of labour to a tax change in Erosa et al. (2016) than in our framework. For example, the heterogeneity in preferences implies that their utility function is not directly comparable to the cases we consider. However, our results also show that the response of our framework is aligned with the reduced-form evidence for a utility function similar to that of Erosa et al. (2016). In particular, using MaC preferences with log consumption and a Frisch elasticity parameter equal to 2, as Erosa et al. (2016), we obtain a measured elasticity of 0.38 in partial equilibrium and 0.3 with general equilibrium effects. As Erosa et al. (2016) discuss, in a lifecycle framework, the distinction between a temporary and a permanent tax change is crucial. That is especially relevant for the Icelandic tax holiday as it combined both temporary and permanent variations of the marginal income tax. Hence, one possible source of differences between Erosa et al. (2016) and our simple framework is the permanent impact of the tax change associated with the tax holiday in Iceland. In most lifecycle models, a permanent change in wages generates a larger response than a temporary one. Another relevant difference is the modelling of both the intensive and extensive margins in Erosa et al. (2016). In frameworks like ours, model labour is usually mapped to annual hours worked in the data. That is, labour 
in the model is a combination of the intensive and extensive margins. Erosa et al. (2016) include non-linearities in the labour supply decision to create an intensive and extensive margin. That non-linear feature can be a relevant ingredient shaping the model's response to a tax decrease depending on how many agents are at the margin, i.e. not supplying labour before the tax cut.

Chetty et al. (2012) use the model in Rogerson and Wallenius (2009) to simulate the Icelandic tax holiday and find that the model overpredicts the employment response observed in the data. It is crucial to highlight that the experiment of Chetty et al. (2012) does not focus on the response of aggregate labour (intensive and extensive margin) but only on the extensive margin. Rogerson and Wallenius (2009) use a much simpler non-linearity than Erosa et al. (2016) to generate the distinction between extensive and intensive margin. In particular, they assume that a minimum number of hours have to be supplied to generate income. One way to interpret the results of Chetty et al. (2012) is to see the calibration/modelling of this margin in Rogerson and Wallenius (2009) as inconsistent with the data. Erosa et al. (2016) show that their strategy to model the extensive margin is aligned with the overall response of aggregate labour due to the tax holiday. Interestingly, Chetty et al. (2012) point out that the response of the model is driven by the set of agents at the margin. That is, the model has too many agents who start working during the tax holiday. However, Sigurdsson (2020) finds that the data indicates that people who are at the margin (young adults and people close to retirement) are key to understand the response of aggregate labour in the data.

We draw two main conclusions from comparing our results to those in the literature. First, it is essential to clarify the mapping between model and data in terms of intensive and extensive margins. More often than not, macro models simply map model aggregate labour into data on total annual hours worked, adding up the intensive and extensive margins. In this case, our framework suggests that there is ample potential for these models to be consistent with the reduced-form evidence (the experiment in Erosa et al. (2016) points in the same direction). On the other hand, the results in Chetty et al. (2012) indicate that replicating the differential responses at the intensive and extensive margins might be more complicated, at least for the model in Rogerson and Wallenius (2009). Secondly, it is crucial to understand that the Frischelasticity parameter is not the only factor shaping the response of aggregate labour to a tax change in most models. That is especially relevant for those models with non-linearities in the labour supply decision. Hence, it is perhaps unwarranted to draw a straight line between the reduced-form estimates and the value of the Frisch-elasticity parameter in structural models.

\section{Aggregate Labour over the Business Cycle}

Another element of dispute in the discussion about the Frisch elasticity is its role in shaping labour fluctuations over the business cycle. In macro models, the usual channel generating business cycles is a shock in the total factor productivity (TFP). As it is the case with the tax elasticity of aggregate labour, the model response to a TFP shock is potentially determined by many model ingredients, including the Frisch-elasticity parameter. It is straightforward to derive the TFP elasticity of aggregate labour using our framework. ${ }^{18}$ Let us denote $\hat{a}_{t}$ the change in

\footnotetext{
${ }^{18}$ All the steps to derive the results we report in this section are in Appendix Section B.3.
} 
total factor productivity with respect to the steady state. In partial equilibrium, we obtain:

$$
\frac{\hat{h}_{t}}{\hat{a}_{t}}=\frac{1}{\Psi_{u}+\Psi_{c}(1-\alpha) \frac{y}{c}}\left(1-\Psi_{c} \frac{y}{c}\right),
$$

while including general equilibrium effects yields:

$$
\frac{\hat{h}_{t}}{\hat{a}_{t}}=\frac{1}{\Psi_{u}+\Psi_{c}(1-\alpha) \frac{y}{c}+\alpha}\left(1-\Psi_{c} \frac{y}{c}\right)
$$

These expressions clarify that the Frisch-elasticity parameter is the sole driver of TFP elasticity in partial equilibrium and with $\Psi_{c}=0$ (as with GHH preferences). In all other cases, there are more model elements involved. In particular, the income effect can dampen or amplify the TFP elasticity analogously to what we see for the tax elasticity. Thus, it is also important to be explicit about the economy's structure to link the reduced-form evidence and the model response to a TFP shock.

\begin{tabular}{|c|c|c|c|c|}
\hline & \multicolumn{2}{|c|}{ GHH preferences } & \multicolumn{2}{|c|}{ MaC preferences } \\
\hline & $\mathrm{PE}$ & GE & $\mathrm{PE}$ & GE \\
\hline Canada & {$[1.00,3.00]$} & {$[0.73,1.42]$} & {$[-0.77,0.42]$} & {$[-0.69,0.28]$} \\
\hline France & {$[1.00,3.00]$} & {$[0.76,1.53]$} & {$[-0.73,0.40]$} & {$[-0.66,0.28]$} \\
\hline Germany & {$[1.00,3.00]$} & {$[0.73,1.43]$} & {$[-0.78,0.38]$} & {$[-0.70,0.26]$} \\
\hline Iceland & {$[1.00,3.00]$} & {$[0.73,1.44]$} & {$[-0.74,0.45]$} & {$[-0.66,0.30]$} \\
\hline Italy & {$[1.00,3.00]$} & {$[0.70,1.33]$} & {$[-0.80,0.45]$} & {$[-0.70,0.28]$} \\
\hline Japan & {$[1.00,3.00]$} & {$[0.72,1.37]$} & {$[-0.78,0.43]$} & {$[-0.69,0.28]$} \\
\hline Switzerland & {$[1.00,3.00]$} & {$[0.75,1.48]$} & {$[-0.81,0.27]$} & {$[-0.74,0.19]$} \\
\hline United Kingdom & {$[1.00,3.00]$} & {$[0.74,1.47]$} & {$[-0.68,0.54]$} & {$[-0.61,0.36]$} \\
\hline United States & {$[1.00,3.00]$} & {$[0.76,1.53]$} & {$[-0.68,0.49]$} & {$[-0.62,0.35]$} \\
\hline
\end{tabular}

Table 3: TFP elasticities are generally different from tax elasticities.

Notes: We compute the lower bound of the estimates in the column of GHH preferences in partial equilibrium using Equation 41, in Appendix Section B.3, with $\phi=1$. The upper bound corresponds to $\phi=3$. We apply the same procedure to compute the estimates in the column of GHH preferences in general equilibrium, but we use Equation 48. For the $\mathrm{MaC}$ preferences in partial equilibrium, we use Equation 42, in Appendix Section B.3, to compute a set of measured elasticities implied by the parameter space $\phi \in[1,3] \times \gamma \in[0.5,2.5]$. The lower bound of the range is the minimum of the computed measured elasticities, while the upper bound is the maximum. We apply the same procedure to compute the estimates in the column of $\mathrm{MaC}$ preferences in general equilibrium, but we use Equation 49. We report all parametrisation inputs for all countries in Table 4 in Appendix Section C.

In Table 3, we present the ranges of TFP elasticities that are consistent with the standard parametrisations used in macro models. Analogously to the estimates we present in Table 2, we use Frisch-elasticity parameters between 1 and 3, and risk-aversion parameters between 0.5 and 2.5 to bound the TFP elasticities. ${ }^{19}$ With GHH preferences, the TFP elasticity is the Frisch elasticity in partial equilibrium (see equation 41). In general equilibrium, the response of labour is more muted, as we see with the tax elasticities. The estimates in the MaC columns show that the size of the risk-aversion parameter is a crucial ingredient determining the response of labour.

\footnotetext{
${ }^{19}$ Our analysis uses yearly frequency to obtain directly comparable estimates to the reduced-form evidence. It is common to use shorter frequencies in macro models when generating TFP shocks.
} 
The lower bounds of the estimates for all countries are negative. These estimates are associated with an unusually low level of risk aversion (0.5), but they are illustrative of the effect of this component in the response of aggregate labour.

\section{Conclusion}

We use a simple theoretical framework, which captures the main features of the determination of aggregate labour in standard macro models, to provide a parsimonious illustration of the relationship between the Frisch elasticity in the model and the reduced-form evidence on the response of labour to temporary variations on wages. Generating a tax holiday in the model, our main finding is that the range of values commonly used to parametrise the Frisch elasticity in macro models is consistent with the magnitude of the reduced-form estimates. We focus on tax holidays because they provide the best-suited identification strategy to study the response of aggregate labour to temporary changes in wages among those used in the reduced-form literature.

Chetty et al. (2012) argue that macroeconomists should aim to align the labour responses to temporary wage changes in their models with the reduced-form evidence. We show that the most basic building block of macro models is capable of achieving this goal. 


\section{References}

Marco Bianchi, Bjorn R. Gudmundsson, and Gylfi Zoega. Iceland's Natural Experiment in Supply-Side Economics. American Economic Review, 91(5):1564-1579, December 2001.

Timo Boppart and Per Krusell. Labor Supply in the Past, Present, and Future: A BalancedGrowth Perspective. Journal of Political Economy, 128(1):118-157, January 2020.

Kristine M. Brown. The Link Between Pensions and Retirement Timing: Lessons from California Teachers. Journal of Public Economics, 98:1-14, February 2013.

David Card and Dean R. Hyslop. Estimating the Effects of a Time-Limited Earnings Subsidy for Welfare-Leavers. Econometrica, 73(6):1723-1770, November 2005.

William J. Carrington. The Alaskan Labor Market during the Pipeline Era. Journal of Political Economy, 104(1):186-218, February 1996.

Raj Chetty. Bounds on Elasticities With Optimization Frictions: A Synthesis of Micro and Macro Evidence on Labor Supply. Econometrica, 80(3):969-1018, May 2012.

Raj Chetty, Adam Guren, Day Manoli, and Andrea Weber. Are Micro and Macro Labor Supply Elasticities Consistent? A Review of Evidence on the Intensive and Extensive Margins. American Economic Review, 101(3):471-75, May 2011.

Raj Chetty, Adam Guren, Day Manoli, and Andrea Weber. Does Indivisible Labor Explain the Difference between Micro and Macro Elasticities? A Meta-Analysis of Extensive Margin Elasticities. NBER Macroeconomics Annual, 27(1):1-56, 2012.

Andrés Erosa, Luisa Fuster, and Gueorgui Kambourov. Towards a Micro-Founded Theory of Aggregate Labour Supply. The Review of Economic Studies, 83(3):1001-1039, March 2016.

Daniel Feenberg and Elisabeth Coutts. An Introduction to the TAXSIM Model. Journal of Policy Analysis and Management, 12(1):189-194, Winter 1993.

Jeremy Greenwood, Zvi Hercowitz, and Gregory W. Huffman. Investment, Capacity Utilization, and the Real Business Cycle. American Economic Review, 78(3):402-417, June 1988.

Jonathan Gruber and David A. Wise. Social Security and Retirement Around the World, chapter Introduction and Summary, pages 1-35. University of Chicago Press, February 1999.

Michael Keane and Richard Rogerson. Micro and Macro Labor Supply Elasticities: A Reassessment of Conventional Wisdom. Journal of Economic Literature, 50(2):464-476, June 2012 .

Michael Keane and Richard Rogerson. Reconciling Micro and Macro Labor Supply Elasticities: A Structural Perspective. Annual Review of Economics, 7(1):89-117, August 2015.

Michael P. Keane. Labor Supply and Taxes: A Survey. Journal of Economic Literature, 49(4): 961-1075, December 2011. 
Robert G. King, Charles I. Plosser, and Sergio T. Rebelo. Production, Growth and Business Cycles: I. The Basic Neoclassical MSodel. Journal of Monetary Economics, 21(2):195-232, 1988.

Day Manoli and Andrea Weber. Nonparametric Evidence on the Effects of Financial Incentives on Retirement Decisions. American Economic Journal: Economic Policy, 8(4):160-82, November 2016.

Isabel Z. Martínez, Emmanuel Saez, and Michael Siegenthaler. Intertemporal Labor Supply Substitution? Evidence from the Swiss Income Tax Holidays. American Economic Review, 111(2):506-46, February 2021.

Edward C. Prescott. Why do Americans Work so Much More than Europeans? Working Paper 10316, National Bureau of Economic Research, February 2004.

Richard Rogerson and Johanna Wallenius. Micro and Macro Elasticities in a Life Cycle Model with Taxes. Journal of Economic Theory, 144(6):2277-2292, November 2009.

Jósef Sigurdsson. Labor Supply Responses and Adjustment Frictions: A Tax-Free Year in Iceland. Unpublished Manuscript, December 2020.

Arnaldur Stefánsson. Labor Supply Response to a Tax Holiday: The Take-Home from a Large and Salient Shock. Unpublished Manuscript, August 2019. 


\section{A Equilibrium Definition}

Given a capital share $\alpha$, a labour tax rate $\tau$, a discount factor $\beta$, a depreciation rate $\delta$ and a utility function $U(c, h)$, a stationary competitive equilibrium is a level of consumption $c$, hours worked $h$ and a capital stock $k$ such that:

1. The first-order conditions of the household hold (Equations 1 and 2).

2. The first-order conditions of the firm hold (Equations 3 and 4).

3. The government budget constraint holds (Equation 5).

4. The goods markets clears, i.e. the budget constraint of the representative household holds with equality.

5. The labour market clears by Walras Law.

The equilibrium conditions imply a steady state where the following conditions hold:

$$
\begin{aligned}
\frac{1}{\beta} & =1+\alpha\left(\frac{k}{h}\right)^{\alpha-1}-\delta \text { and }, \\
c & =y-\delta k .
\end{aligned}
$$




\section{B Derivations}

\section{B.1 The Tax Elasticity of Aggregate Labour}

The linearised system of equations that characterizes the equilibrium is:

$$
\begin{array}{r}
-\epsilon_{c} \hat{c}_{t}+\frac{U_{c h}}{U_{c}} h \hat{h}_{t}+\epsilon_{c} \hat{c}_{t+1}-\frac{U_{c h}}{U_{c}} h \hat{h}_{t+1}-\frac{r}{1+r} \hat{r}_{t}=0, \\
\Psi_{u} \hat{h}_{t}+\Psi_{c} \hat{c}_{t}-\hat{w}_{t}+\frac{\tau}{1-\tau} \hat{\tau}_{t}=0, \\
c \hat{c}_{t}+k \hat{k}_{t+1}=w(1-\tau) h\left(\hat{w}_{t}+\hat{h}_{t}-\frac{\tau}{1-\tau} \hat{\tau}_{t}\right)+\frac{k}{\beta} \hat{k}_{t}+r k \hat{r}_{t}+T \hat{T}_{t}, \\
\hat{w}_{t}=\alpha\left(\hat{k}_{t}-\hat{h}_{t}\right), \\
\hat{r}_{t}=(\alpha-1)\left(\hat{k}_{t}-\hat{h}_{t}\right), \text { and } \\
\hat{T}_{t}=\hat{\tau}_{t}+\hat{w}_{t}+\hat{h}_{t} .
\end{array}
$$

\section{Partial Equilibrium}

In partial equilibrium, prices and capital are constant, that is, $\hat{r}_{t}=\hat{w}_{t}=\hat{k}_{t}=0$. Hence, Equations 18, 19, and 20 become:

$$
\begin{array}{r}
\Psi_{u} \hat{h}_{t}+\Psi_{c} \hat{c}_{t}+\frac{\tau}{1-\tau} \hat{\tau}_{t}=0, \\
c \hat{c}_{t}=w(1-\tau) h\left(\hat{h}_{t}-\frac{\tau}{1-\tau} \hat{\tau}_{t}\right)+T \hat{T}_{t}, \text { and } \\
\hat{T}_{t}=\hat{\tau}_{t}+\hat{h}_{t} .
\end{array}
$$

Taking Equation 22, substituting in $\hat{T}_{t}$ from Equation 23, and using $T=\tau w h$ :

$$
\begin{array}{r}
c \hat{c}_{t}=w(1-\tau) h\left(\hat{h}_{t}-\frac{\tau}{1-\tau} \hat{\tau}_{t}\right)+\tau w h\left(\hat{\tau}_{t}+\hat{h}_{t}\right), \\
c \hat{c}_{t}=w h \hat{h}_{t}+w h(1-\tau)\left(-\frac{\tau}{1-\tau} \hat{\tau}_{t}\right)+\tau w h \hat{\tau}_{t}, \\
c \hat{c}_{t}=w h \hat{h}_{t}-w h \tau \hat{\tau}_{t}+\tau w h \hat{\tau}_{t}, \text { which implies, } \\
c \hat{c}_{t}=w h \hat{h}_{t} .
\end{array}
$$

Now use $w h=(1-\alpha) y$ and solve for $\hat{c}_{t}$ :

$$
\hat{c}_{t}=\frac{(1-\alpha) y}{c} \hat{h}_{t} .
$$

The last step is substituting the expression above into Equation 21:

$$
\begin{array}{r}
\Psi_{u} \hat{h}_{t}+\Psi_{c} \frac{(1-\alpha) y}{c} \hat{h}_{t}+\frac{\tau}{1-\tau} \hat{\tau}_{t}=0, \text { which implies } \\
\left(\Psi_{u}+\Psi_{c}(1-\alpha) \frac{y}{c}\right) \hat{h}_{t}=-\frac{\tau}{1-\tau} \hat{\tau}_{t} .
\end{array}
$$


Rearranging, we find that the partial equilibrium $(P E)$ tax elasticity of aggregate labour is:

$$
\epsilon^{P E}=\frac{\hat{h}_{t}}{\hat{\tau}_{t}}=-\frac{\tau}{1-\tau} \frac{1}{\Psi_{u}+\Psi_{c}(1-\alpha) \frac{y}{c}} .
$$

\section{General Equilibrium}

In this case, prices are flexible while capital remains at its steady-state level $\left(\hat{k}_{t}=0\right)$. The relevant Equations from the equilibrium definition (Equations 18-20) are now:

$$
\begin{array}{r}
\Psi_{u} \hat{h}_{t}+\Psi_{c} \hat{c}_{t}-\hat{w}_{t}+\frac{\tau}{1-\tau} \hat{\tau}_{t}=0, \\
c \hat{c}_{t}=w(1-\tau) h\left(\hat{w}_{t}+\hat{h}_{t}-\frac{\tau}{1-\tau} \hat{\tau}_{t}\right)+r k \hat{r}_{t}+T \hat{T}_{t}, \\
\hat{w}_{t}=-\alpha \hat{h}_{t}, \\
\hat{r}_{t}=(1-\alpha) \hat{h}_{t}, \text { and } \\
\hat{T}_{t}=\hat{\tau}_{t}+\hat{w}_{t}+\hat{h}_{t} .
\end{array}
$$

Using Equation 28, substituting in $\hat{r}_{t}$ from Equation 30 and $\hat{T}_{t}$ from Equation 31, and using $T=\tau w h$, we obtain:

$$
c \hat{c}_{t}=w(1-\tau) h\left(\hat{w}_{t}+\hat{h}_{t}-\frac{\tau}{1-\tau} \hat{\tau}_{t}\right)+r k(1-\alpha) \hat{h}_{t}+\tau w h\left(\hat{\tau}_{t}+\hat{w}_{t}+\hat{h}_{t}\right) .
$$

Because $\hat{\tau}_{t}$ terms cancel out, and following the same simplifications as in Equations 24-25:

$$
c \hat{c}_{t}=(w h+r k(1-\alpha)) \hat{h}_{t}+w h \hat{w}_{t}
$$

Using the labour demand (Equation 29) to substitute out $\hat{w}_{t}$ :

$$
\begin{array}{r}
c \hat{c}_{t}=(w h+r k(1-\alpha)) \hat{h}_{t}+w h\left(-\alpha \hat{h}_{t}\right), \\
c \hat{c}_{t}=(1-\alpha)(w h+r k) \hat{h}_{t}, \\
c \hat{c}_{t}=(1-\alpha) y \hat{h}_{t}, \text { which implies, } \\
\hat{c}_{t}=(1-\alpha) \frac{y}{c} \hat{h}_{t} .
\end{array}
$$

We plug the above expression, as well as the labour demand (Equation 29) into Equation 27:

$$
\begin{array}{r}
\Psi_{u} \hat{h}_{t}+\Psi_{c}(1-\alpha) \frac{y}{c} \hat{h}_{t}+\alpha \hat{h}_{t}+\frac{\tau}{1-\tau} \hat{\tau}_{t}=0, \text { which implies, } \\
\left(\Psi_{u}+\Psi_{c}(1-\alpha) \frac{y}{c}+\alpha\right) \hat{h}_{t}=-\frac{\tau}{1-\tau} \hat{\tau}_{t} .
\end{array}
$$

We get the tax elasticity of aggregate labour:

$$
\epsilon=\frac{\hat{h}_{t}}{\hat{\tau}_{t}}=-\frac{\tau}{1-\tau} \frac{1}{\Psi_{u}+\Psi_{c}(1-\alpha) \frac{y}{c}+\alpha} .
$$




\section{GHH Preferences}

The period utility over consumption $\left(c_{t}\right)$ and labour $\left(h_{t}\right)$ is given by:

$$
U\left(c_{t}, h_{t}\right)=\frac{1}{1-\gamma}\left(c_{t}-\frac{h_{t}^{1+1 / \phi}}{1+1 / \phi}\right)^{1-\gamma}
$$

where $\phi>0$ denotes the Frisch elasticity, and $\gamma$ the risk aversion. For GHH preferences, we have $\frac{U_{h}}{U_{c}}=\frac{U_{c h}}{U_{c c}}=\frac{U_{h c}}{U_{c c}}$ and the Frisch elasticity $\epsilon_{u}=\frac{U_{h}}{h\left(U_{h h}-\frac{U_{c h}^{2}}{U_{c c}}\right)}=\phi$. This implies,

$$
\Psi_{u}=\left(\frac{1}{\epsilon_{u}}+\frac{h}{U_{h}}\left(\frac{U_{h c}^{2}}{U_{c c}}-\frac{U_{h}}{U_{c}} U_{c h}\right)\right)=\frac{1}{\epsilon_{u}}=\frac{1}{\phi} .
$$

With $\frac{U_{c c}}{U_{c}}=\frac{U_{c h}}{U_{h}}=\frac{U_{h c}}{U_{h}}$ and the Arrow-Pratt measure of relative risk aversion $\epsilon_{c}=-\frac{U_{c c} c}{U_{c}}$, we get,

$$
\Psi_{c}=\left(c \frac{U_{h c}}{U_{h}}+\epsilon_{c}\right)=0
$$

Plugging $\Psi_{u}=\frac{1}{\phi}$ and $\Psi_{c}=0$ into Equations 26 and 32, we obtain the tax elasticities of aggregate labour with GHH preferences:

$$
\begin{aligned}
\epsilon_{G H H}^{P E} & =-\frac{\tau}{1-\tau} \phi, \text { and } \\
\epsilon_{G H H} & =-\frac{\tau}{1-\tau} \frac{1}{\frac{1}{\phi}+\alpha} .
\end{aligned}
$$

\section{MaC Preferences}

The period utility over consumption $\left(c_{t}\right)$ and labour $\left(h_{t}\right)$ is given by:

$$
U\left(c_{t}, h_{t}\right)=\frac{c_{t}^{1-\gamma}}{1-\gamma}-\frac{h_{t}^{1+1 / \phi}}{1+1 / \phi}
$$

where $\phi>0$ denotes the Frisch elasticity, and $\gamma$ the risk aversion. MaC preferences are separable, so $U_{c h}=U_{h c}=0$. This implies,

$$
\begin{aligned}
\Psi_{u} & =\left(\frac{1}{\epsilon_{u}}+\frac{h}{U_{h}}\left(\frac{U_{h c}^{2}}{U_{c c}}-\frac{U_{h}}{U_{c}} U_{c h}\right)\right)=\frac{1}{\epsilon_{u}}=\frac{1}{\phi}, \text { and } \\
\Psi_{c} & =\left(c \frac{U_{h c}}{U_{h}}+\epsilon_{c}\right)=\epsilon_{c}=-\frac{U_{c c} c}{U_{c}}=\gamma .
\end{aligned}
$$

Plugging $\Psi_{u}=\frac{1}{\phi}$ and $\Psi_{c}=\gamma$ into Equations 26 and 32, we obtain the tax elasticities of aggregate labour with $\mathrm{MaC}$ preferences:

$$
\begin{aligned}
\epsilon_{M a C}^{P E} & =-\frac{\tau}{1-\tau} \frac{1}{\frac{1}{\phi}+\gamma(1-\alpha) \frac{y}{c}}, \text { and } \\
\epsilon_{M a C} & =-\frac{\tau}{1-\tau} \frac{1}{\frac{1}{\phi}+\gamma(1-\alpha) \frac{y}{c}+\alpha} .
\end{aligned}
$$




\section{B.2 The Tax Elasticity of Aggregate Labour with a Richer Tax System Measured in a Tax Holiday}

The richer tax system means that $\tau=\frac{\tau^{i n c}+\tau^{s s}+\tau^{c}}{1+\tau^{c}}$ and $1-\tau=\frac{1-\tau^{i n c}-\tau^{s s}}{1+\tau^{c}}$. Using the new tax structure, Equation 26, and the tax holiday definition $\left(\hat{\tau}_{t}^{\text {inc }}=-1\right)$, we obtain the tax elasticity of aggregate labour measured in a tax holiday in partial equilibrium:

$$
\xi^{P E}=\frac{\tau^{i n c}}{1-\tau^{i n c}-\tau^{s s}} \frac{1}{\Psi_{u}+\Psi_{c}(1-\alpha) \frac{y}{c}} .
$$

Using Equation 32, we obtain its counterpart with general equilibrium effects:

$$
\xi=\frac{\tau^{i n c}}{1-\tau^{i n c}-\tau^{s s}} \frac{1}{\Psi_{u}+\Psi_{c}(1-\alpha) \frac{y}{c}+\alpha} .
$$

As we show in Section B.1, with GHH preferences, $\Psi_{u}=\frac{1}{\phi}$ and $\Psi_{c}=0$. Hence,

$$
\begin{aligned}
& \xi_{\mathrm{GHH}}^{P E}=\frac{\tau^{i n c}}{1-\tau^{i n c}-\tau^{s s}} \phi, \text { and } \\
& \xi_{\mathrm{GHH}}=\frac{\tau^{i n c}}{1-\tau^{i n c}-\tau^{s s}} \frac{1}{\frac{1}{\phi}+\alpha}
\end{aligned}
$$

With MaC preferences, $\Psi_{u}=\frac{1}{\phi}$ and $\Psi_{c}=\gamma$, which implies,

$$
\begin{aligned}
\xi_{\mathrm{MaC}}^{P E} & =\frac{\tau^{i n c}}{1-\tau^{i n c}-\tau^{s s}} \frac{1}{\frac{1}{\phi}+\gamma(1-\alpha) \frac{y}{c}}, \text { and } \\
\xi_{\mathrm{MaC}} & =\frac{\tau^{i n c}}{1-\tau^{i n c}-\tau^{s s}} \frac{1}{\frac{1}{\phi}+\gamma(1-\alpha) \frac{y}{c}+\alpha}
\end{aligned}
$$

\section{B.3 The TFP Elasticity of Aggregate Labour}

Denote $\hat{a}_{t}$ the percentage change in factor neutral TFP. The TFP enters the model via the firstorder conditions of the firm, $\hat{a}_{t}=\hat{w}_{t}=\hat{r}_{t}$. The linearised system of equations that characterizes the economy with the full tax system and a TFP shock are:

$$
\begin{array}{r}
-\epsilon_{c} \hat{c}_{t}+\frac{U_{c h}}{U_{c}} h \hat{h}_{t}+\epsilon_{c} \hat{c}_{t+1}-\frac{U_{c h}}{U_{c}} h \hat{h}_{t+1}-\frac{r}{1+r} \hat{r}_{t}=0, \\
\Psi_{u} \hat{h}_{t}+\Psi_{c} \hat{c}_{t}-\hat{w}_{t}+\frac{\tau^{i n c}}{1-\tau^{i n c}-\tau^{s s}} \hat{\tau}_{t}^{i n c}=0, \\
c \hat{c}_{t}+k \hat{k}_{t+1}=w(1-\tau) h\left(\hat{w}_{t}+\hat{h}_{t}-\frac{\tau^{i n c}}{1-\tau^{i n c}-\tau^{s s}} \hat{\tau}_{t}^{i n c}\right)+\frac{k}{\beta} \hat{k}_{t}+r k \hat{r}_{t}+T \hat{T}_{t}, \\
\hat{w}_{t}=\hat{a}_{t}+\alpha\left(\hat{k}_{t}-\hat{h}_{t}\right), \\
\hat{r}_{t}=\hat{a}_{t}+(\alpha-1)\left(\hat{k}_{t}-\hat{h}_{t}\right), \text { and } \\
\hat{T}_{t}=\frac{\tau^{i n c}}{\tau^{i n c}+\tau^{s s}+\tau^{c}} \hat{\tau}_{t}^{i n c}+\hat{w}_{t}+\hat{h}_{t} .
\end{array}
$$




\section{Partial Equilibrium}

In partial equilibrium, prices and capital are constant: $\hat{r}_{t}=\hat{w}_{t}=\hat{a}_{t}$ and $\hat{k}_{t}=0$. Equations 33, 34 , and 35 become:

$$
\begin{array}{r}
\Psi_{u} \hat{h}_{t}+\Psi_{c} \hat{c}_{t}-\hat{a}_{t}+\frac{\tau^{i n c}}{1-\tau^{i n c}-\tau^{s s}} \hat{\tau}_{t}^{i n c}=0, \\
c \hat{c}_{t}=w(1-\tau) h\left(\hat{a}_{t}+\hat{h}_{t}-\frac{\tau^{i n c}}{1-\tau^{i n c}-\tau^{s s}} \hat{\tau}_{t}^{i n c}\right)+r k \hat{a}_{t}+T \hat{T}_{t}, \text { and } \\
\hat{T}_{t}=\frac{\tau^{i n c}}{\tau^{i n c}+\tau^{s s}+\tau^{c}} \hat{\tau}_{t}^{i n c}+\hat{a}_{t}+\hat{h}_{t} .
\end{array}
$$

In Equation 37, we substitute in $\hat{T}_{t}$ from Equation 38, and use $T=\tau w h$ :

$$
\begin{array}{r}
c \hat{c}_{t}=w(1-\tau) h\left(\hat{a}_{t}+\hat{h}_{t}-\frac{\tau^{i n c}}{1-\tau^{i n c}-\tau^{s s}} \hat{\tau}_{t}^{i n c}\right)+r k \hat{a}_{t}+ \\
\tau w h\left(\frac{\tau^{i n c}}{\tau^{i n c}+\tau^{s s}+\tau^{c}} \hat{\tau}_{t}^{i n c}+\hat{a}_{t}+\hat{h}_{t}\right), \text { which implies } \\
c \hat{c}_{t}=w h \hat{h}_{t}+w h(1-\tau)\left(\hat{a}_{t}-\frac{\tau^{i n c}}{1-\tau^{i n c}-\tau^{s s}} \hat{\tau}_{t}^{i n c}\right)+r k \hat{a}_{t}+\tau w h\left(\frac{\tau^{i n c}}{\tau^{i n c}+\tau^{s s}+\tau^{c}} \hat{\tau}_{t}^{i n c}+\hat{a}_{t}\right) .
\end{array}
$$

The $\hat{\tau}_{t}^{i n c}$ terms cancel out, which results in:

$$
\begin{array}{r}
c \hat{c}_{t}=w h\left(\hat{a}_{t}+\hat{h}_{t}\right)+r k \hat{a}_{t}, \text { and } \\
c \hat{c}_{t}=w h \hat{h}_{t}+(w h+r k) \hat{a}_{t} .
\end{array}
$$

We use $w h=(1-\alpha) y$ and $(w h+r k)=y$ and solve for $\hat{c}_{t}$ :

$$
\begin{array}{r}
c \hat{c}_{t}=(1-\alpha) y \hat{h}_{t}+y \hat{a}_{t}, \text { and } \\
\hat{c}_{t}=(1-\alpha) \frac{y}{c} \hat{h}_{t}+\frac{y}{c} \hat{a}_{t} .
\end{array}
$$

Lastly, we substitute the above expression into the Equation 36:

$$
\begin{array}{r}
\Psi_{u} \hat{h}_{t}+\Psi_{c}\left((1-\alpha) \frac{y}{c} \hat{h}_{t}+\frac{y}{c} \hat{a}_{t}\right)-\hat{a}_{t}+\frac{\tau^{i n c}}{1-\tau^{i n c}-\tau^{s s}} \hat{\tau}_{t}^{i n c}=0, \text { which implies } \\
\left(\Psi_{u}+\Psi_{c}(1-\alpha) \frac{y}{c}\right) \hat{h}_{t}=-\frac{\tau^{i n c}}{1-\tau^{i n c}-\tau^{s s}} \hat{\tau}_{t}^{i n c}+\left(1-\Psi_{c} \frac{y}{c}\right) \hat{a}_{t} .
\end{array}
$$

Assuming no income tax change $\left(\hat{\tau}_{t}^{i n c}=0\right)$, we derive the partial equilibrium TFP elasticity of aggregate labour:

$$
\frac{\hat{h}_{t}}{\hat{a}_{t}}=\frac{1}{\Psi_{u}+\Psi_{c}(1-\alpha) \frac{y}{c}}\left(1-\Psi_{c} \frac{y}{c}\right) .
$$

For GHH preferences, we obtain:

$$
\frac{\hat{h}_{t}}{\hat{a}_{t}}=\phi
$$


while for MaC preferences, we get:

$$
\frac{\hat{h}_{t}}{\hat{a}_{t}}=\frac{1}{\frac{1}{\phi}+\gamma(1-\alpha) \frac{y}{c}}\left(1-\gamma \frac{y}{c}\right) .
$$

\section{General Equilibrium}

We now allow prices to change but keep capital at its steady-state level $\left(\hat{k}_{t}=0\right)$. The relevant equations from the equilibrium definition are now:

$$
\begin{array}{r}
\Psi_{u} \hat{h}_{t}+\Psi_{c} \hat{c}_{t}-\hat{w}_{t}+\frac{\tau^{i n c}}{1-\tau^{i n c}-\tau^{s s}} \hat{\tau}_{t}^{i n c}=0, \\
c \hat{c}_{t}=w(1-\tau) h\left(\hat{w}_{t}+\hat{h}_{t}-\frac{\tau^{i n c}}{1-\tau^{i n c}-\tau^{s s}} \hat{\tau}_{t}^{i n c}\right)+r k \hat{r}_{t}+T \hat{T}_{t}, \\
\hat{w}_{t}=\hat{a}_{t}-\alpha \hat{h}_{t}, \\
\hat{r}_{t}=\hat{a}_{t}+(1-\alpha) \hat{h}_{t}, \text { and } \\
\hat{T}_{t}=\frac{\tau^{i n c}}{\tau^{i n c}+\tau^{s s}+\tau^{c}} \hat{\tau}_{t}^{i n c}+\hat{w}_{t}+\hat{h}_{t} .
\end{array}
$$

In Equation 44, we substitute in $\hat{r}_{t}$ from Equation 46 and $\hat{T}_{t}$ from Equation 47, and use $T=\tau w h$ :

$$
\begin{aligned}
c \hat{c}_{t}= & w(1-\tau) h\left(\hat{w}_{t}+\hat{h}_{t}-\frac{\tau^{i n c}}{1-\tau^{i n c}-\tau^{s s}} \hat{\tau}_{t}^{i n c}\right)+r k\left(\hat{a}_{t}+(1-\alpha) \hat{h}_{t}\right) \\
& +\tau w h\left(\frac{\tau^{i n c}}{\tau^{i n c}+\tau^{s s}+\tau^{c}} \hat{\tau}_{t}^{i n c}+\hat{w}_{t}+\hat{h}_{t}\right) .
\end{aligned}
$$

We replace $\tau$ and $1-\tau$ with the full tax system, then the $\hat{\tau}_{t}^{i n c}$ terms cancel out:

$$
c \hat{c}_{t}=(w h+r k(1-\alpha)) \hat{h}_{t}+w h \hat{w}_{t}+r k \hat{a}_{t} .
$$

We use the labour demand (Equation 45$)$ to substitute out $\hat{w}_{t}$ :

$$
\begin{array}{r}
c \hat{c}_{t}=(w h+r k(1-\alpha)) \hat{h}_{t}+w h\left(\hat{a}_{t}-\alpha \hat{h}_{t}\right)+r k \hat{a}_{t}, \\
c \hat{c}_{t}=(1-\alpha)(w h+r k) \hat{h}_{t}+(w h+r k) \hat{a}_{t}, \\
c \hat{c}_{t}=(1-\alpha) y \hat{h}_{t}+y \hat{a}_{t}, \text { which implies } \\
\hat{c}_{t}=(1-\alpha) \frac{y}{c} \hat{h}_{t}+\frac{y}{c} \hat{a}_{t} .
\end{array}
$$

We plug the above expression as well as the labour demand (Equation 45) into Equation 43:

$$
\begin{array}{r}
\Psi_{u} \hat{h}_{t}+\Psi_{c}\left((1-\alpha) \frac{y}{c} \hat{h}_{t}+\frac{y}{c} \hat{a}_{t}\right)-\left(\hat{a}_{t}-\alpha \hat{h}_{t}\right)+\frac{\tau^{i n c}}{1-\tau^{i n c}-\tau^{s s}} \hat{\tau}_{t}^{i n c}=0, \text { which implies } \\
\left(\Psi_{u}+\Psi_{c}(1-\alpha) \frac{y}{c}+\alpha\right) \hat{h}_{t}=-\frac{\tau^{i n c}}{1-\tau^{i n c}-\tau^{s s}} \hat{\tau}_{t}^{i n c}+\left(1-\Psi_{c} \frac{y}{c}\right) \hat{a}_{t} .
\end{array}
$$

Assuming no changes in income taxes $\left(\hat{\tau}_{t}^{i n c}=0\right)$, we get the general equilibrium TFP elasticity of aggregate labour:

$$
\frac{\hat{h}_{t}}{\hat{a}_{t}}=\frac{1}{\Psi_{u}+\Psi_{c}(1-\alpha) \frac{y}{c}+\alpha}\left(1-\Psi_{c} \frac{y}{c}\right)
$$


Using GHH, the TFP elasticity is:

$$
\frac{\hat{h}_{t}}{\hat{a}_{t}}=\frac{1}{\frac{1}{\phi}+\alpha},
$$

while for $\mathrm{MaC}$ preferences, it is:

$$
\frac{\hat{h}_{t}}{\hat{a}_{t}}=\frac{1}{\frac{1}{\phi}+\gamma(1-\alpha) \frac{y}{c}+\alpha}\left(1-\gamma \frac{y}{c}\right) .
$$




\section{Data Inputs to Parametrise the G-7 Countries}

Table 4: Data inputs to parametrise the framework to G-7 countries.

\begin{tabular}{lcccc} 
& $\frac{c}{y}$ & $\alpha$ & $\tau^{s s}$ & $\tau^{i n c}$ \\
\hline \hline Canada & 0.73 & 0.37 & 0.08 & 0.26 \\
France & 0.006 & 0.003 & 0.001 & 0.003 \\
Germany & 0.73 & 0.32 & 0.31 & 0.21 \\
& 0.004 & 0.001 & 0.002 & 0.003 \\
Iceland & 0.71 & 0.37 & 0.30 & 0.20 \\
& 0.003 & 0.004 & 0.003 & 0.003 \\
Italy & 0.76 & 0.36 & 0.07 & 0.31 \\
& 0.007 & 0.013 & 0.001 & 0.004 \\
Japan & 0.74 & 0.42 & 0.25 & 0.26 \\
Switzerland & 0.005 & 0.003 & 0.003 & 0.005 \\
United Kingdom & 0.74 & 0.40 & 0.20 & 0.12 \\
& 0.007 & 0.002 & 0.005 & 0.002 \\
United States & 0.65 & 0.34 & 0.10 & 0.22 \\
& 0.006 & 0.003 & 0.001 & 0.001 \\
& 0.003 & 0.35 & 0.13 & 0.25 \\
& 0.80 & 0.32 & 0.001 & 0.002 \\
& 0.003 & 0.004 & 0.001 & 0.20 \\
\hline
\end{tabular}

Notes: We compute all inputs following the methodology detailed in Prescott (2004). We compute the value for each input for all years between 2000 and 2015, and then compute the mean for the relevant period. For $\frac{c}{y}, 2004$ and 2005 are omitted in the average for Iceland as there is no data on aggregate consumption. For $\alpha$ and $\tau^{i n c}, 2015$ is omitted in the averages for Iceland as the data required to compute these variables is not available. We report the standard errors of the estimates in brackets. 